\title{
EFFECT OF FASTING ON LIVER ENZYMES IN PATIENTS USING METHOTREXATE: COHORT STUDY
}

\author{
Reza Farrokhseresht ${ }^{1}$, Saideh Ariannia ${ }^{2}$, Reza Hadizadeh Neisanghalb ${ }^{3}$
}

1: M.D., Assistant Professor of Rheumatology, Department of Internal Medicine, Shahid Mohammadi Clinical Research Development Center, Hormozgan University of Medical Sciences, Bandar Abbas, Iran

2: M.D., Assistant Professor of Rheumatology, Department of Rheumatology, Tehran University of Medical Sciences, Tehran, Iran

3: M.D., Internist, Infectious and Tropical Diseases Research Center, Hormozgan Health Institute, Hormozgan University of Medical Sciences, Bandar Abbas, Iran

\section{TYPE OF ARTICLE: ORIGINAL ARTICLE}

\begin{abstract}
Introduction: Ramadan fasting has several advantages in regards to different diseases. However, its role in chronic diseases and patients who are under treatment with specific medications remains unknown. The general objective of this study was to determine the effect of Ramadan fasting on liver function tests in patients using methotrexate attending Shahid Mohammadi Hospital in 2015.

Methods: This cohort study was conducted on patients under treatment with methotrexate in the Rheumatology Center, Bandar Abbas, Iran. Fifty patients were placed in fasting group and 50 in a non-fasting group. Patients were evaluated for liver function tests, including aspartate aminotransferase, alanine aminotransferase, alkaline phosphatase, and total bilirubin before and after Ramadan fasting. For data analysis, IBM SPSS version 22.0 and descriptive tests, independent samples T-test and paired samples T-test were used.

Results: Liver function tests were similar in two groups before Ramadan fasting $(p>0.05)$. Also, liver function tests were not statistically different between two groups after Ramadan fasting $(p>0.05)$. In the fasting and nonfasting group, there was no statistically significant difference between liver function tests before and after Ramadan fasting $(p>0.05)$.

Conclusion: The effect of Ramadan fasting on liver function tests in rheumatologic patients using methotrexate is not statistically and clinically significant. However, we recommend nutritional instructions for patients using methotrexate for Ramadan fasting.

KEYWORDS: Ramadan fasting, Methotrexate, Liver function tests
\end{abstract}

\section{INTRODUCTION}

Fasting is avoidance of Muslims to eat and drink from dayspring to vesper. Several studies have reported advantages of Ramadan fasting in regards to different diseases (1-4). However, the role of fasting in patients especially who are using specific types of medications is not adequately discussed. In some chronic diseases, Ramadan fasting may be associated with no disadvantages, but, in severe diseases or in end stages, Ramadan fasting may be associated with high risk of complications. For example, a recent study has reported worsening of renal function with Ramadan fasting in stage 3 or higher chronic kidney diseases (5). One study has evaluated the effect of fasting on cirrhotic patients. Based on the results of this study Ramadan fasting is associated with changes in portal blood flow. However, these changes have no long-term disadvantages on liver function in these individuals (6). Liver has the capacity of adaptation with Ramadan fasting (7). However, some studies have reported the higher rates of gastrointestinal bleeding, and peptic ulcer diseases with Ramadan fasting in patients with chronic liver diseases (8). Fasting has a role in decreasing inflammation and improving cell protection. Fasting in individuals with chronic diseases and in patients who are using medications with liver metabolism can alter the metabolism of medications

\section{Correspondence:}

Dr. Reza Hadizadeh Neisanghalb, Infectious and Tropical Diseases Research Center, Hormozgan University of Medical Sciences, Bandar Abbas, Iran. Tel: +98.9111351689, E-mail: Rezahn1979@gmail.com

Received: August 8, 2016, Accepted: September 24, 2016, Published: December 2016

iThenticate screening: August 11, 2016, English editing: September 29, 2016, Quality control: Novembr 17, 2016

(C) 2016 The Authors. This is an open access article under the terms of the Creative Commons Attribution-NonCommercialNoDerivs License, which permits use and distribution in any medium, provided the original work is properly cited, the use is non-commercial and no modifications or adaptations are made. 
and disease activity. Several studies have shown decrease in levels of liver enzymes after fasting and improvement in lipid profile and blood pressure. Rheumatologic patients are frequently using medications with liver metabolism including methotrexate. Methotrexate is an antimetabolite and anti-folate medication, which is widely used in rheumatology and autoimmune diseases. Due to liver metabolism of methotrexate increase in liver enzymes and hepatotoxicity is probable. Several studies have reported advantages of fasting but few have investigated its role during using medications. The general objective of the current study was to determine the effect of fasting on liver enzymes in patients using methotrexate in Bandar Abbas in 2015. The specific objectives include comparison of liver enzymes in methotrexate users before and after fasting according to age, gender, medication dose, underlying disease, and medication combination.

\section{MATERIAL AND METHODS}

\subsection{Research design and participants}

The cohort study was conducted on patients referred to Rheumatology Center, Shahid Mohammadi Hospital, Bandar Abbas, Iran, between June and July 2015. Inclusion criteria were ages between 20 to 70 years old and methotrexate treatment. Patients were excluded from the study in the first group if they were unable to fast because of acute phase of the disease or other conditions. Also, patients in the second group were excluded if they had more than three days of fasting during the study period.

\subsection{Sampling}

For sample size calculation, a sample size of at least 82 were calculated considering a standard deviation of 8 U/L in each group based on our pilot study of aminotransferase levels in patients using methotrexate in a pilot study, least difference of $5 \mathrm{U} / \mathrm{L}$ in level of aminotransferases in two groups, confidence interval of $95 \%$, and power of $80 \%$. Therefore, we selected 100 patients for participation in the study considering the possibility of loss of follow-up in the study population. Convenience sampling was used for this study. All patients with rheumatoid arthritis, systemic lupus erythematous, and other rheumatologic disorders, who were using methotrexate, were included in our study. In the fasting group, we have included patients who were under treatment with methotrexate and decided to fast during Ramadan month. In the non-fasting group, we included patients who were under treatment with methotrexate who did not decided to fast during Ramadan month.

\subsection{Data collection}

The patients were classified into two equal groups. The first group had fasting for 16 hours a day for 29 days with nutritional recommendation of physician. The second group had no fasting. The patients were assessed for liver function tests before Ramadan month and at the end of Ramadan month. A 10cc venous blood sample was obtained from each patient for determining liver function tests including aspartate aminotransferase (AST), alanine aminotransferase (ALT), alkaline phosphatase (ALP), and total bilirubin levels. The tests were done using Pars Azmoon kits in reference laboratory of the Hormozgan University of Medical Sciences.

\subsection{Study instrument}

A checklist, including identification data, age, gender, weight, underlying disease, medications, medication dose ( $<7.5 \mathrm{mg}$ per week or $>7.5 \mathrm{mg}$ per week), smoking status, history of alcohol consumption, and laboratory test results, was completed for each patient.

\subsection{Research ethics}

The research proposal was confirmed by the Ethics Committee of the Hormozgan University of Medical Sciences (Research Code: 94104). Written informed consent was obtained from each patient after explanation of the study protocol.

\subsection{Statistical analyses}

The collected data were included in IBM SPSS Statistics for Windows (Version 22.0. Armonk, NY: IBM Corp) and were analyzed using paired sample T-tes and independent samples T-test. A $p$-value less than 0.05 was assumed to be significant.

\section{RESULTS}

\subsection{Baseline characteristics}

We included 100 patients in our study. Among the $50(50 \%)$ were in fasting, and $50(50 \%)$ were in the non-fasting group. Mean age of the participants was $43.7 \pm 11.7$ years. 


\subsection{Effect of fasting on AST level}

AST level was not significantly different in fasting and non-fasting groups before Ramadan $(p=0.700)$ (Table 1). Also, AST levels were not significantly different in the fasting and non-fasting group after Ramadan $(p=0.124)$. Also, there was no significant difference in AST level before and after study in fasting $(p=0.459)$ and non-fasting $(p=0.639)$ groups (Table 1$)$.

\subsection{Effect of fasting on ALT level}

The ALT level was not significantly different in fasting and non-fasting groups before Ramadan $(p=0.462)$ (Table 1). Also, the ALT level was similar in both groups after Ramadan $(p=0.239)$. The ALT level was not significantly different in the fasting group before and after Ramadan $(p=0.123)$. Also in the non-fasting group, the ALT level was not significantly different before and after Ramadan $(p=0.352)$ (Table 1$)$.

\subsection{Effect of fasting on ALP}

The level of Alp was not significantly different before study in the fasting and non-fasting groups $(p=0.584)$. After Ramadan, we also found no significant difference in Alp level in fasting and non-fasting groups $(p=0.741)$. Also, Alp level was not significantly different in the fasting group before and after Ramadan $(p=0.926)$. Alp level was also similar before and after Ramadan in the non-fasting group $(p=0.417)$ (Table 1$)$.

\subsection{Effect of fasting on total bilirubin}

Total bilirubin was similar before study in the fasting and non-fasting groups $(p=0.803)$ (Table 1). Also, total bilirubin level was similar after Ramadan in the fasting and non-fasting groups $(p=0.687)$. In the fasting group, there was no significant difference in total bilirubin level before and after study $(p=0.636)$. Also, there was no significant difference between total bilirubin before and after study in the non-fasting group $(p=0.953)$ (Table 1).

Table 1. Effect of Ramadan fasting on aspartate aminotransferase (AST), alanine aminotransferase (ALT), alkaline phosphatase (ALP), and total bilirubin levels

\begin{tabular}{|l|l|l|l|l|}
\hline \multicolumn{2}{|l|}{ Variables } & $\begin{array}{l}\text { Fasting } \\
(n=50)\end{array}$ & $\begin{array}{l}\text { Non-fasting } \\
(n=50)\end{array}$ & $p$-value* \\
\hline \multirow{3}{*}{ AST levels (U/L) } & AST levels before Ramadan & $22 \pm 6.1$ & $20 \pm 4.5$ & 0.700 \\
\cline { 2 - 5 } & AST levels after Ramadan & $22.6 \pm 8.1$ & $20.4 \pm 5.9$ & 0.124 \\
\cline { 2 - 5 } & $p$-value (paired samples t-test) & 0.459 & 0.639 & \\
\hline \multirow{3}{*}{ ALT levels (U/L) } & ALT levels before Ramadan & $20.5 \pm 7.5$ & $19.5 \pm 6.8$ & 0.462 \\
\cline { 2 - 5 } & ALT levels after Ramadan & $23.6 \pm 11$ & $21.2 \pm 9.6$ & 0.239 \\
\cline { 2 - 5 } & $p$-value (paired samples t-test) & 0.123 & 0.352 & \\
\hline \multirow{3}{*}{ ALP levels (U/L) } & Alp levels before Ramadan & $182 \pm 34.8$ & $187.1 \pm 42.6$ & 0.584 \\
\cline { 2 - 5 } & Alp levels after Ramadan & $182.7 \pm 35.2$ & $182.2 \pm 39.5$ & 0.741 \\
\cline { 2 - 5 } & $p$-value (paired samples t-test) & 0.926 & 0.417 & \\
\hline Total bilirubin levels (mg/dl) & Total bilirubin levels before Ramadan & $1.18 \pm 0.5$ & $1.20 \pm 0.5$ & 0.803 \\
\cline { 2 - 5 } & Total bilirubin levels after Ramadan & $1.16 \pm 0.48$ & $1.20 \pm 0.5$ & 0.687 \\
\cline { 2 - 5 } & $p$-value (paired samples t-test) & 0.636 & 0.953 & \\
\hline
\end{tabular}

* Independent samples t-test

\section{DISCUSSION}

In this study, we have evaluated the effect of Ramadan fasting on liver function tests in patients under treatment with methotrexate. We found no significant effect for Ramadan fasting on the liver function tests in patients using methotrexate. Few studies have reported the effect of Ramadan fasting on liver function tests. In one recent study, Nasiri et al. reported that Ramadan fasting can significantly alter the liver function tests (9), but, as concluded by authors, these changes are not clinically important because the levels of enzymes and other liver functions tests are still in normal ranges. Therefore, it seems that the effect of Ramadan on liver function tests is clinically nonsignificant. Nutritional education during Ramadan fasting can prevent some complications (10). However, we found in our study no significant effect of Ramadan fasting on liver function tests in patients using methotrexate, but we recommend that the rheumatologic patients who are using methotrexate to be educated about nutritional recommendations during Ramadan fasting. Our study results should be interpreted with caution. Our patients were not divided into two groups randomly. They were divided into two groups based on their decision to fast or not. 
Although there was no difference between two groups in baseline characteristics, other factors may be different in the two groups, which can influence the study results. We were unable to follow the patients for long-term effects of fasting on their liver function tests. Rheumatologic diseases are often chronic conditions and need long-term medication use. Therefore, more studies with longer term of follow-up are recommended.

\section{CONCLUSIONS}

The effect of Ramadan fasting of liver function tests in patients with rheumatologic diseases under treatment with methotrexate is not statistically or clinically significant. Despite this, we recommend nutritional instructions to the patients by the physicians for Ramadan fasting. Long-term follow-up of the patients who are under treatment with methotrexate to evaluate the effect of Ramadan fasting on liver function tests are recommended.

\section{ACKNOWLEDGMENTS:}

This manuscript was extracted from a thesis for obtaining a specialist degree in internal medicine by Dr. Reza Hadizadeh (Thesis Code: 198). The authors want to thank to Shahid Mohammadi Clinical Research Development Center in Hormozgan University of Medical Sciences in Bandar Abbas, Iran.

\section{CONFLICT OF INTEREST:}

There is no conflict of interest to be declared.

\section{AUTHORS' CONTRIBUTIONS:}

All authors contributed to this project and article equally. All authors read and approved the final manuscript.

\section{REFERENCES:}

1) Turin TC, Ahmed S, Shommu NS, Afzal AR, Al Mamun M, Qasqas M, et al. Ramadan fasting is not usually associated with the risk of cardiovascular events: A systematic review and meta-analysis. J Family Community Med. 2016; 23(2): 73-81. doi: 10.4103/2230-8229.181006. PMid: 27186152. PMCid: PMC4859102.

2) Soori M, Mohaghegh S, Hajain M, Moraadi B. Effects of Ramadan Fasting on Inspiratory Muscle Function. Asian J Sports Med. 2016; 7(3): e35201. doi: 10.5812/asjsm.35201. PMid: 27826401. PMCid: PMC5098160.

3) Sezen Y, Altiparmak IH, Erkus ME, Kocarslan A, Kaya Z, Gunebakmaz O, et al. Effects of Ramadan fasting on body composition and arterial stiffness. J Pak Med Assoc. 2016; 66(12): 1522-7. PMid: 27924959.

4) Sassi M, Chakroun T, Chouchene S, Hellara I, Boubaker H, Grissa MH, et al. Does Lipid Profile Affect Thrombin Generation During Ramadan Fasting in Patients With Cardiovascular Risks? Clin Appl Thromb Hemost. 2016: 1076029616665920. doi: 10.1177/1076029616665920. PMid: 27613563.

5) Bakhit AA, Kurdi AM, Wadera JJ, Alsuwaida AO. Effects of Ramadan fasting on moderate to severe chronic kidney disease. A prospective observational study. Saudi Med J. 2017; 38(1): 48-52. doi: 10.15537/smj.2017.1.17566. PMid: 28042630.

6) Mohamed SY, Emara MH, Hussien HI, Elsadek HM. Changes in portal blood flow and liver functions in cirrhotics during Ramadan fasting in the summer; a pilot study. Gastroenterol Hepatol Bed Bench. 2016; 9(3): 180-8. PMid: 27458510. PMCid: PMC4947132.

7) Farooq N, Priyamvada S, Arivarasu NA, Salim S, Khan F, Yusufi AN. Influence of Ramadan-type fasting on enzymes of carbohydrate metabolism and brush border membrane in small intestine and liver of rat used as a model. Br J Nutr. 2006; 96(6): 1087-94. PMid: 17181884.

8) Elnadry MH, Nigm IA, Abdel Aziz IM, Elshafee AM, Elazhary SS, Abdel Hafeez MA, et al. Effect of Ramadan fasting on Muslim patients with chronic liver diseases. J Egypt Soc Parasitol. 2011 Aug; $41(2)$ : 337-46. PMid: 21980772.

9) Nasiri JM, Kheiri SP, Khoshdel AM, Boroujeni AJP. Effect of Ramadan Fast on Liver Function Tests. Iran J Med Sci. 2016; 41(5): 459-60. PMid: 27582598. PMCid: PMC4967493.

10) Shadman Z, Akhoundan M, Poorsoltan N, Khoshniat Nikoo M, Larijani B, Akhgar Zhand C, et al. Nutritional Education Needs in Relation to Ramadan Fasting and Its Complications in Tehran, Iran. Iran Red Crescent Med J. 2016; 18(8): e26130. doi: 10.5812/ircmj.26130. PMid: 27781112. PMCid: PMC5066803. 